\title{
Extracellular matrix remodeling genes polymorphisms and risk of chronic bronchitis and recurrent pneumonia in children
}

\author{
Gulnaz Faritovna Korytina ${ }^{1}$, Leysan Zinurovna Akhmadishina ${ }^{1}$, Elena Vitalievna Viktorova ${ }^{2}$, \\ Olga Sergeevna Tselousova ${ }^{1,3}$, Ksenia Vladimirovna Danilko ${ }^{3}$, Olga Vladimirovna Kochetova ${ }^{1}$ \\ and Tatyana Victorovna Viktorova ${ }^{1,3}$
}

\begin{abstract}
We investigated the association of matrix metalloproteinases, the disintegrin and metalloprotease 33 and the tissue and serum inhibitors of proteinase gene polymorphisms with severe chronic respiratory diseases in Tatar children. We analyzed the case-control data sample from a total of 592 Tatar individuals, consisting of 119 children with chronic bronchitis, 138 with recurrent pneumonia and 335 control children residing in Ufa (Russia). The percentage of heterozygous genotype for the MMP9 $(2660 \mathrm{~A}>\mathrm{G})$ was higher among healthy children $\left(52.54 \%\right.$ vs $36.13 \%$ in chronic bronchitis patients, $P_{\text {adj }}=0.0033$, $P_{\text {cor }}=0.033$, odds ratio $(\mathrm{OR})=0.51$; and $36.96 \%$ in recurrent pneumonia group, $P_{\text {adj }}=0.0034, P_{\text {cor }}=0.034,0 R=0.53$ ). The MMP12 $(-82 \mathrm{~A}>\mathrm{G})$ locus was associated with chronic bronchitis in the additive model $\left(P_{\mathrm{adj}}=0.0091, P_{\text {cor }}=0.09\right.$, $\mathrm{OR}=0.45, \beta=-0.798)$. The relationship between the 6A6A genotype of MMP3 $(-11715 \mathrm{~A}>6 \mathrm{~A})\left(P_{\mathrm{adj}}=0.0013\right.$, $\left.P_{\text {cor }}=0.013,0 R=3.91\right)$ and the 6A-A haplotype of MMP3 $(-11715 \mathrm{~A}>6 \mathrm{~A})$ and $M M P 12(-82 \mathrm{~A}>\mathrm{G})$ and recurrent pneumonia were unraveled $\left(P_{\mathrm{adj}}=0.001, P_{\mathrm{cor}}=0.01, \mathrm{OR}=2.07\right)$. This haplotype was also associated with a higher risk of chronic bronchitis $\left(P_{\mathrm{adj}}=0.0012, P_{\text {cor }}=0.012, \mathrm{OR}=2.15\right)$. The TIMP3 $(-1296 \mathrm{~T}>\mathrm{C})$ was associated with recurrent pneumonia in the dominant model $\left(P_{\mathrm{adj}}=0.0031, P_{\text {cor }}=0.031, \mathrm{OR}=1.91\right)$. The MMP9, MMP3 and TIMP3 (tissue inhibitors of matrix metalloproteinases) polymorphisms and MMP3 and MMP12 haplotypes may play a substantial role in susceptibility to severe airway and lung injury in children with chronic bronchitis and recurrent pneumonia.
\end{abstract}

Journal of Human Genetics (2013) 58, 467-474; doi:10.1038/jhg.2013.24; published online 11 April 2013

Keywords: association analysis; children; chronic respiratory disease; inhibitors of proteinases; matrix metalloproteinases

\section{INTRODUCTION}

Hereditary predisposition is an important risk factor for chronic respiratory diseases. ${ }^{1}$ In the recent years, the genetic mechanisms underlying such wide-spread diseases such as chronic obstructive pulmonary disease (COPD) and bronchial asthma have been extensively investigated worldwide. ${ }^{1,2}$ Several genome-wide association studies of COPD and bronchial asthma identified new genomic loci associated with these diseases. ${ }^{1-4}$ At the same time, little is known about the genetic basis of chronic respiratory diseases in children, except for asthma, cystic fibrosis, early-onset emphysema associated with severe $\alpha_{1}$-antitrpypsin deficiency, some rare hereditary syndromes and congenital lung abnormalities and defects. ${ }^{5-7}$ The role of hereditary factors in susceptibility to acute community-acquired and nosocomial pneumonia in adults is also being actively investigated. ${ }^{8}$ Chronic respiratory diseases with mostly bilateral involvement of small respiratory pathways and lung parenchyma constitute one of the topical issues in pediatric and general medicine., ${ }^{9,10}$ In chronic bronchitis, airway obstruction results from chronic and excessive secretion of abnormal airway mucus, inflammation, bronchospasm and infections. ${ }^{5,11}$ Pneumonia, or inflammation of the lungs, is the most common type of infectious disease of the lung. Irreversible morphological changes, accompanied by relapses of inflammation in the lungs and airways, are typical for relapsing pneumonia. ${ }^{5,9,11}$ Chronic inflammatory process impairs growth, development and functioning of the lungs and bronchi. ${ }^{10}$

Increased activity of proteolytic enzymes because of genetic variation, their enhanced expression or impaired regulation by protease inhibitors bring about destruction of endothelial and epithelial cells of the lung parenchyma, remodeling of respiratory pathways and deterioration of alveolar structures. All these processes critically contribute to the pathogenesis of respiratory diseases. ${ }^{12}$ Genetic variants of matrix metalloproteinase (MMPs) and disintegrin metalloproteinase 33 (ADAM33) genes were shown to affect the susceptibility to bronchial asthma, COPD, lung cancer,

${ }^{1}$ Department of Genomics, Institute of Biochemistry and Genetics, Ufa Scientific Center, Ufa, Russian Federation; ${ }^{2}$ Georg-August University of Goettingen, Goettingen, Germany and ${ }^{3}$ Bashkortostan State Medical University, Ufa, Russian Federation

Correspondence: Dr GF Korytina, Department of Genomics, Institute of Biochemistry and Genetics, Ufa Scientific Center, Pr. Oktybry, 71, Ufa 450054, Russian Federation. E-mail: Guly_kory@mail.ru

Received 4 October 2012; revised 5 March 2013; accepted 11 March 2013; published online 11 April 2013 
interstitial lung fibrosis and acute respiratory distress syndrome. ${ }^{13-18}$ MMP is a family of proteolytic enzymes; in human, it includes 26 zinc-dependent endopeptidases. ${ }^{19}$ MMPs are involved in cell migration in the course of tissue regeneration, wound repair and inflammation by promoting leukocyte migration through vessel walls and tissue remodeling. In the lung, MMPs destroy molecules of the extracellular matrix (ECM), including growth factors, chemokines, proteases and cell adhesion molecules. ${ }^{19,20}$ MMPs are secreted by several cell types, in particular, by alveolar macrophages and epithelial cells. ${ }^{19}$ ADAM33 belongs to the ADAM (A Disintegrin And Metaloprotease) family of membrane-bound proteolytic enzymes of the adamalysin family of the metzincin subcluss (zinc-dependent metalloproteinases). ADAMs are involved in intercellular interactions and proteolysis. ${ }^{21}$ ADAM33 polymorphisms have been associated with accelerated lung function decrease, as well as with COPD and bronchial asthma, respiratory pathway hyperreactivity and aggravated inflammatory response in COPD. ${ }^{21-24}$ MMP and ADAM activity depends on their interactions with TIMPs and with serum inhibitors of proteolytic enzymes, which play a key role in ECM homeostasis by regulating the MMP activity. ${ }^{25}$ The major enzymes of the protease inhibitor system are as follows: $\alpha 1$-antitrypsin, $\alpha 1$-antichymotrypsin, $\alpha 2$-macroglobulin and TIMPs. ${ }^{6}$ $\alpha 1$-Antitrypsin is the main inhibitor of neutrophilic elastase, trypsin, chymotrypsin and collagenase. The $\alpha 1$-antitrypsin deficiency develops because of a defect in gene SERPINA1. $\alpha 1$-Antichymotrypsin is another important enzyme that inhibits pancreatic chymotrypsin, neutrophilic cathepsin G, mast cell chymase and superoxide ion production in neutrophils. Several point mutations in the SERPINA3 gene have been detected. ${ }^{6}$ The family of TIMPs includes several enzymes (TIMP1, TIMP2, TIMP3 and TIMP4) that play a key role in ECM homeostasis by regulating the MMP activity. TIMPs interact with MMPs by forming complexes with slightly varying affinities to different MMPs. ${ }^{25}$

We hypothesized that polymorphic variants of the genes functioning in the remodeling of airflow pathways and alveolar destruction are associated with chronic bronchitis and recurrent pneumonia in children. Therefore, we studied MMP1, MMP2, MMP3, MMP9, MMP12, ADAM33, TIMP2, TIMP3, SERPINA1 and SERPINA3 gene polymorphisms in Tatar children with chronic respiratory disease and healthy subjects to determine whether multiple polymorphisms of these genes are involved in the development of chronic bronchitis and recurrent pneumonia of children.

\section{MATERIALS AND METHODS}

\section{Patients and controls}

The study group consisted of a total of 257 Tatar children. Among them, there were 119 children with chronic bronchitis and 138 with relapsing pneumonia recruited from 2004 to 2010 years in the Republican Children's Hospital (Ufa, Russia). A summary of the study is provided in Table 1. For all patients with chronic bronchitis and recurrent pneumonia, the diagnosis and detection was carried out by the hospital specialists on the basis of the medical histories and the results of general, clinical, and special tests (chest X-ray, spirometry measures and fibrobronchoscopy), physical examination and laboratory approaches. Children with chronic bronchitis had disseminated defeats of bronchi accompanied by productive cough (more than 3 months a year), and constant heterogeneous wheezes in the lungs (during several months) in the presence of two or three exacerbations a year in the course of 2 years (J41, according to the International Statistical Classification of Diseases and Related Health Problems, Tenth Revision (ICD-10), http://www.who.int/classifications/ icd/en/). ${ }^{26}$ The chronic bronchitis group, who suffered from bronchitis without obstruction and endobronchial inflammation, was diagnosed visually by bronchoscopy. None of the subjects in the study sample had a pulmonary infiltrate in the X-ray or were diagnosed as having bronchial asthma (obstructive bronchitis). Irreversible morphological changes (deformation of bronchi and
Table 1 Characteristics of the study groups

\begin{tabular}{|c|c|c|c|c|}
\hline & \multicolumn{3}{|c|}{ Diseased children } & \multirow[b]{2}{*}{$\begin{array}{l}\text { Healthy } \\
\text { children }\end{array}$} \\
\hline & $\begin{array}{c}\text { All } \\
\text { patients }\end{array}$ & $\begin{array}{l}\text { Chronic } \\
\text { bronchitis }\end{array}$ & $\begin{array}{l}\text { Relapsing } \\
\text { pneumonia }\end{array}$ & \\
\hline Female & 134 (52.14\%) & $61(51.26 \%)$ & 73 (52.90\%) & $182(54.33 \%)$ \\
\hline Male & $123(47.86 \%)$ & $58(48.74 \%)$ & $65(47.10 \%)$ & $153(45.67 \%)$ \\
\hline Age (years) \pm s.d. & $12.44 \pm 3.96$ & $12.28 \pm 2.12$ & $11.57 \pm 1.71$ & $15.51 \pm 3.44$ \\
\hline Ethnicity & $\begin{array}{c}\text { Caucasian, } \\
\text { Tatar }\end{array}$ & $\begin{array}{c}\text { Caucasian, } \\
\text { Tatar }\end{array}$ & $\begin{array}{c}\text { Caucasian, } \\
\text { Tatar }\end{array}$ & $\begin{array}{c}\text { Caucasian, } \\
\text { Tatar }\end{array}$ \\
\hline Total no. of cases & 257 & 119 & 138 & 335 \\
\hline
\end{tabular}

Abbreviation: s.d., standard deviation.

pneumosclerosis in one or several segments of the lung) accompanied by relapses of inflammation in the lung tissue and airways (three or four exacerbations in a year) are revealed in cases with patients having frequently recurring (relapsing) pneumonia (J18, according to the ICD-10). ${ }^{26}$ The duration of disease in cases of children with chronic bronchitis and recurrent pneumonia was from 5 to 11 years. Subjects were excluded if they had a history of asthma (according to the GINA project), atopy (skin-prick testing and a high level of total serum immunoglobulin E), cystic fibrosis (based on clinical features, a positive result for sweat test (confidence interval (CI) $>60 \mathrm{mmoll}^{-1}$ ) and detection of CFTR gene mutations), as well as tuberculosis (based on clinical features and a positive result for the test for Mycobacterium tuberculosis). Primary ciliary dyskinesia, cellular or humoral immune deficiencies, gastroesophageal reflux disease, anatomic anomalies of the airways and congenital heart disease were excluded if clinically indicated. For the control group, DNA samples from 335 unrelated, healthy, age- and sex-matched Tatar children inhabiting in Ufa were obtained. All the controls were collected among those children who attended Republican Children's Hospital for regular medical examination. These individuals had no records of respiratory or other related chronic diseases. Before implementation, this study was approved by the Independent Ethics Committee (IEC) of the Institute of Biochemistry and Genetics, Ufa Scientific Centre of Russian Academy of Sciences (Ufa, Russia), and all subjects (their parents or lawful representatives) gave their informed consent. All DNA samples used in the study were anonymous.

DNA was isolated from peripheral blood leukocytes using the standard phenol-chloroform extraction procedure. $^{27}$ Polymorphisms of MMP1 $(-1607 \mathrm{G}>\mathrm{GG}, \quad \mathrm{rs} 1799750$ and $-519 \mathrm{~A}>\mathrm{G}, \quad \mathrm{rs} 494379), M M P 2 \quad(-735 \mathrm{C}>\mathrm{T}$, rs2285053), MMP3 (-1171 5A $>6 \mathrm{~A}, \quad$ rs35068180), MMP9 $(-1562 \mathrm{C}>\mathrm{T}$, rs3918242 and $2660 \mathrm{~A}>\mathrm{G}, \quad$ rs17576), $M M P 12 \quad(-82 \mathrm{~A}>\mathrm{G}, \quad$ rs2276109), ADAM33 (12418A $>\mathrm{G}$, rs2280091 and 13491C $>\mathrm{G}, \quad$ rs2787094), TIMP2 $(-418 \mathrm{G}>\mathrm{C}, \quad \mathrm{rs} 8179090), \quad$ TIMP3 $\quad(-1296 \mathrm{~T}>\mathrm{C}, \quad$ rs9619311), SERPINA1 (1237G $>$ A, rs2073333, 2313A $>$ T, rs17580 and (4628A $>$ G, rs28929474) and SERPINA3 (25G > A, rs4934) were analyzed by polymerase chain reaction and subsequent cleavage with restriction endonuclease MroXI, KpnI, Hinfl, Tth111I, SphI, SmaI, PvuI (SibEnzyme, Novosibirsk, Russia), NcoI, Eco88I (Fermentas, Lithuania) and AluBI, TaqI, Hinfl (SibEnzyme) as per the manufacturer's instruction. Polymerase chain reaction was performed with TaqDNA polymerase (SibEnzyme) under standard conditions in the MJ Mini thermal cycler (BioRad, Hercules, CA, USA). Primers and allele identification algorithms were described previously in refs $6,13,16,22,28-33$. The DNA fragment obtained by polymerase chain reaction and endonuclease digestion were analyzed by polyacrylamide gel electrophoresis in a 6-8\% gel (acrylamide:methylenebisacrylamide, 29:1) in Tris/Borate/EDTA, at 200-300 V $\left(10 \mathrm{~V} \mathrm{~cm}^{-1}\right)$. Gels were stained with $0.1 \mu \mathrm{g} \mathrm{ml}^{-1}$ ethidium bromide for $15 \mathrm{~min}$ and photographed in ultraviolet light. Alleles were identified using a 100-bp molecular size marker (SibEnzyme).

\section{Statistical analysis}

For quantitative traits, mean values and standard errors ( $\mathrm{M} \pm$ s.e.) were calculated; group comparison was performed with a nonparametric 
Mann-Whitney $U$-test. The frequencies of qualitative traits were compared using Pearson's $\chi^{2}$ test. Statistical analysis was carried out with the Statistica v. 6.0 program (StatSoft Inc., Tulsa, OK, USA) (http://www.statistica.com). Minor allele frequencies (MAFs) and the agreement of the genotype distribution to the Hardy-Weinberg equilibrium $\left(\chi^{2}\right)$ were determined using the PLINK software, v. 1.07 (http://pngu.mgh.harvard.edu/ purcell/plink/contact. shtml\#cite). The association analysis using the basic allele test and the calculation of the odds ratio (OR) for the rare allele of each locus and the significance of intergroup differences in allele and genotype frequencies ( $\chi^{2}$ test for sample heterogeneity and the $P$-value) was also performed with PLINK v. 1.07 (http://pngu.mgh.harvard.edu/ purcell/plink/contact.shtml\# cite). Differences were considered significant if their corresponding $P$-values were $<0.05$. To control Type I error rate, Bonferroni correction for multiple comparison was performed, meaning that $P$-value was multiplied by the number of single-nucleotide polymorphism (SNP) loci studied $(n=10)$ to obtain the new $P_{\text {cor }}$ value. Logistic regression was used to detect the association of SNPs and haplotypes of linked loci in different models; that is, additive, dominant, recessive, accounting for quantitative and binary traits (sex, age), which were introduced into the regression equation as additional variables. The significance of independent factors was assessed using the Wald $z$-statistic coefficient and the respective $P$-value. The exponent of an individual regression coefficient $(\beta)$ was interpreted as the OR for the logistic model and the $95 \%$ cCIl was calculated. The significance of the obtained model accounting for all variables was verified by the significance of the likelihood ratio test $\left(P_{\text {adj }}\right)$. The best model was chosen using the Akaike's information criterion. For each significant locus $(P<0.05)$, the model with lowest Akaike's information criterion was chosen. The regression analysis was performed with PLINK v. 1.07 and SNPStats packages (http://pngu.mgh.harvard.edu/ purcell/plink/ contact.shtml\#cite and http://bioinfo.iconcologia.net/SNPstats_web). The haplotype frequencies and standard linkage disequilibrium coefficient $\left(D^{\prime}\right)$, as well as intergroup differences in haplotype frequencies, were calculated with Haploview 4.2 (http://www.broadinstitute.org).

\section{RESULTS}

Systematic quality control procedures were performed to guarantee a high quality of the data. Subsequently, SNPs were filtered according to their proportion of missing data, MAF or deviation from HardyWeinberg equilibrium within the controls. For the control group, the following results were obtained: MMP1 (-1607G $>\mathrm{GG})$ $(P=0.002862, \quad \mathrm{MAF}=0.388), \quad M M P 1 \quad(-519 \mathrm{~A}>\mathrm{G}) \quad(P=0.0008$, $\mathrm{MAF}=0.404), \quad M M P 2 \quad(-735 \mathrm{C}>\mathrm{T}) \quad(P=0.3456, \quad \mathrm{MAF}=0.106)$, MMP3 $\quad(-1171 \quad 5 \mathrm{~A}>6 \mathrm{~A}) \quad(P=0.3947, \quad \mathrm{MAF}=0.066), \quad M M P 9$ $(-1562 \mathrm{C}>\mathrm{T}) \quad(P=1, \quad \mathrm{MAF}=0.12), \quad M M P 9 \quad(2660 \mathrm{~A}>\mathrm{G})$ $(P=0.02439, \quad \mathrm{MAF}=0.339), \quad M M P 12 \quad(-82 \mathrm{~A}>\mathrm{G}) \quad(P=0.3992$, $\mathrm{MAF}=0.107), A D A M 33(12418 \mathrm{~A}>\mathrm{G}) \quad(P=0.2364, \mathrm{MAF}=0.177)$, ADAM33 $\quad(13491 \mathrm{C}>\mathrm{G}) \quad(P=0.04715, \quad \mathrm{MAF}=0.344), \quad$ TIMP2 $(-418 \mathrm{G}>\mathrm{C}) \quad(P=0.01065, \quad \mathrm{MAF}=0.0070), \quad$ TIMP3 $\quad(-1296 \mathrm{~T}>\mathrm{C})$ $(P=1, \quad \mathrm{MAF}=0.259), \quad$ SERPINA1 $\quad(1237 \mathrm{G}>\mathrm{A}) \quad(P=0.4197$, $\mathrm{MAF}=0.046)$, SERPINA1 $(4628 \mathrm{~A}>\mathrm{G})(P=1, \mathrm{MAF}=0.0070)$, SERPINA1 $(2313 \mathrm{~A}>\mathrm{T})(P=1, \mathrm{MAF}=0.0020)$ and SERPINA3 $(25 \mathrm{G}>\mathrm{A})$ $(P=0.1662, \mathrm{MAF}=0.486)$. The SNPs MMP1 $(-1607 \mathrm{G}>\mathrm{GG})$ and MMP1 $(-519 \mathrm{~A}>\mathrm{G})$, with a genotype distribution that differs significantly from the Hardy-Weinberg equilibrium in the control group, and TIMP2 $(-418 \mathrm{G}>\mathrm{C})$, SERPINA1 $(4628 \mathrm{~A}>\mathrm{G})$ and SERPINA1 $(2313 \mathrm{~A}>\mathrm{T})$, with a minor allele frequency below 0.01 , were excluded from the analysis.

We obtained data on the allele and genotype frequency distributions in children with chronic bronchitis, recurrent pneumonia and in healthy children (Tables 2 and 3). The groups of children with chronic bronchitis and healthy children differed significantly in the allele and genotype frequency distributions of MMP12 $(-82 \mathrm{~A}>\mathrm{G})$ and MMP9 $(2660 \mathrm{~A}>\mathrm{G})$, while children with recurrent pneumonia differed from the control group in the allele and genotype frequencies of MMP3
$(-11715 \mathrm{~A}>6 \mathrm{~A})$, ADAM33 (13491C $>\mathrm{G})$, MMP9 $(2660 \mathrm{~A}>\mathrm{G})$ and TIMP3 $(-1296 \mathrm{~T}>\mathrm{C})$. Further association analysis and calculation of OR and significance levels in different models was performed only for this set of candidate loci.

In the chronic bronchitis patient group, the frequency of GG genotype of the MMP9 $(2660 \mathrm{~A}>\mathrm{G})$ increased twofold $(14.29 \%$ vs $7.63 \%$ in control, $P_{\text {adj }}=0.05, \mathrm{OR}=2.02$, in recessive model); however, the difference became insignificant after the correction for multiple comparisons $\left(P_{\text {cor }}=0.5\right)$. MMP9 $(2660 \mathrm{~A}>\mathrm{G})$ was associated with recurrent pneumonia in the dominant model $(P=0.029$, $\left.P_{\text {cor }}=0.29, \mathrm{OR}=0.62\right)$. The percentage of heterozygous genotype for the MMP9 $(2660 \mathrm{~A}>\mathrm{G})$ was higher among healthy children $\left(52.54 \%\right.$ vs $36.13 \%$ in chronic bronchitis patients, $P_{\text {adj }}=0.0033$, $P_{\text {cor }}=0.033, \mathrm{OR}=0.51$; and $36.96 \%$ in recurrent pneumonia group, $P_{\text {adj }}=0.0034, P_{\text {cor }}=0.034$, OR $\left.=0.53\right)$.

The $-1562 \mathrm{C}>\mathrm{T}(\mathrm{rs} 3918242)$ and $2660 \mathrm{~A}>\mathrm{G}$ (rs17576) MMP9 haplotype frequency distributions in COPD patients and healthy individuals were similar. Strong linkage disequilibrium between two MMP9 markers was found, and the values of normalized linkage disequilibrium coefficient (Lewontin's coefficient), $D^{\prime}$, reflecting the strength of disequilibrium between two markers in chronic bronchitis and recurrent pneumonia constituted 0.847 and 0.773 , respectively (see Table 4).

The frequency of the minor $G$ allele of $M M P 12(-82 A>G)$ appeared to decrease in children with chronic bronchitis $\left(P_{\text {adj }}=0.0237, P_{\text {cor }}=0.237, \mathrm{OR}=0.48\right)$ by performing the classical allelic test (Table 2). The MMP12 $(-82 \mathrm{~A}>\mathrm{G})$ locus showed association with chronic bronchitis testing in the dominant risk genotype model $\left(P_{\mathrm{adj}}=0.01, P_{\mathrm{cor}}=0.10, \mathrm{OR}=0.45\right)$. The risk of chronic bronchitis in children was associated with the presence of the frequent A allele $(\mathrm{OR}=2.201 ; 95 \% \mathrm{CI}: 1.16-4.17)$. The lowest Akaike's information criteria testing the association of this genotype was obtained for the additive model with corresponding $P_{\mathrm{adj}}=0.0091$, $P_{\text {cor }}=0.09, \mathrm{OR}=0.45$ and $\beta=-0.798$.

In children with recurrent pneumonia, the frequency of the $5 \mathrm{~A}$ allele of $M M P 3 \quad(-11715 \mathrm{~A}>6 \mathrm{~A})$ was significantly decreased $\left(P_{\text {adj }}=0.006, P_{\text {cor }}=0.06, \mathrm{OR}=0.27\right)$. The 6A6A genotype was significantly associated with recurrent pneumonia in children $\left(P_{\text {adj }}=0.0013, P_{\text {cor }}=0.013\right.$, OR $\left.=3.91\right)$.

As both associated markers, MMP12 and MMP3, belong to the same linkage disequilibrium block on chromosome 11q22-q23, we analyzed the haplotype frequencies of these polymorphisms in genes in cases and healthy controls (Table 5). On the basis of the results of the haplotype frequency analysis, we conclude that chronic bronchitis and recurrent pneumonia groups differ significantly from healthy individuals in their haplotype frequency distribution. The percentage of the 6A-A haplotype by MMP3 (-1171 5A>6A) and MMP12 $(-82 \mathrm{~A}>\mathrm{G})$ was higher among children who were disease carriers (91.18\% in chronic bronchitis vs $83.26 \%$ in control, $P_{\text {adj }}=0.0012$, $P_{\text {cor }}=0.012, \quad \mathrm{OR}=2.15$ and $90.94 \%$ in recurrent pneumonia vs $83.26 \%$ in control, $\left.P_{\text {adj }}=0.001, P_{\text {cor }}=0.01, \mathrm{OR}=2.07\right)$.

The 6A-G haplotype by MMP3 $(-11715 \mathrm{~A}>6 \mathrm{~A})$ and $M M P 12$ $(-82 \mathrm{~A}>\mathrm{G})$ was a marker of chronic bronchitis resistance $(5.46 \%$ vs $10.33 \%$ in control, $P_{\text {adj }}=0.017, P_{\text {cor }}=0.17, O R=0.46$ ), and the $5 \mathrm{~A}-\mathrm{A}$ haplotype was a marker of recurrent pneumonia resistance $\left(1.81 \%\right.$ vs $5.94 \%$ in control, $\left.P_{\text {adj }}=0.0077, P_{\text {cor }}=0.07, \mathrm{OR}=0.46\right)$. However, the difference became insignificant after the correction for multiple testing.

The frequency of the $\mathrm{T}$ allele of TIMP3 $(-1296 \mathrm{~T}>\mathrm{C})$ was significantly increased in patients with recurrent pneumonia $\left(83.70 \%\right.$ vs $74.13 \%$ in controls, $\left.P_{\text {adj }}=0.003, P_{\text {cor }}=0.03, \mathrm{OR}=1.79\right)$. 
Table 2 Allele and genotype frequencies of the proteolytic system and protease inhibitor gene polymorphisms in chronic bronchitis and healthy subjects

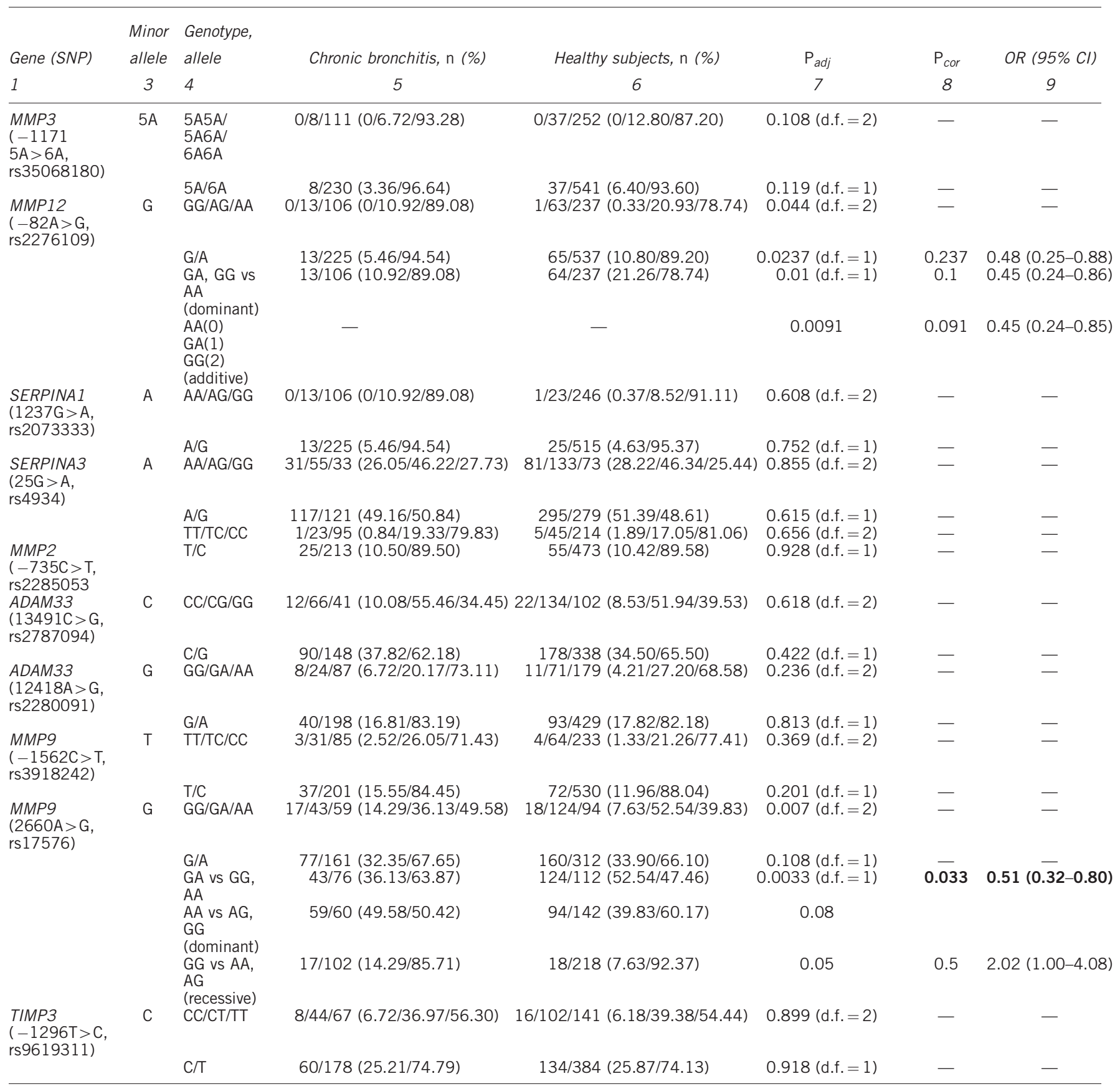

Abbreviations: $\mathrm{Cl}$, confidence interval; d.f., degrees of freedoms; OR, odds ratio.

$P_{\text {adj }}$, significance in the likelihood ratio test for the regression model adjusted for sex and age;

$P_{\text {corr }}$, significance after the Bonferroni correction for multiple testing.

Bold numerals in the table indicate that the difference was significant after the correction for multiple comparisons.

Significant association of TIMP3 $(-1296 \mathrm{~T}>\mathrm{C})$ polymorphism with recurrent pneumonia in children was detected using the dominant model $\left(P_{\text {adj }}=0.0031, P_{\text {cor }}=0.031, \mathrm{OR}=1.91\right)$. The rare $\mathrm{C}$ allele of TIMP3 $(-1296 \mathrm{~T}>\mathrm{C})$ was a marker of resistance to recurrent pneumonia in children $\left(P_{\mathrm{adj}}=0.0015, P_{\text {cor }}=0.015, \quad \mathrm{OR}=0.55\right.$, $\beta=-0.59$ ) for the additive risk genotype model.

In children with recurrent pneumonia, the portion of GG homozygotes of ADAM33 (13491C $>\mathrm{G})$ polymorphism was as high as $50.72 \%$ in comparison to $39.53 \%$ in healthy children $\left(P_{\mathrm{adj}}=0.033\right.$,
$\left.P_{\text {cor }}=0.33, \mathrm{OR}=1.57\right)$. On the other hand, the frequency of the heterozygous CG genotype of ADAM33 (13491C > G) was $51.94 \%$ in controls in comparison to $38.41 \%$ in chronic bronchitis patients $\left(P_{\text {adj }}=0.0099, P_{\text {cor }}=0.099\right.$, OR $\left.=0.58\right)$.

\section{DISCUSSION}

Inflammation plays a central role in the pathogenesis of chronic respiratory diseases, as it is the major cause of all functional and morphological changes. Impaired regulation of the inflammatory 
Table 3 Allele and genotype frequencies of the proteolytic system and tissue protease inhibitor gene polymorphisms in relapsing pneumonia and healthy subjects

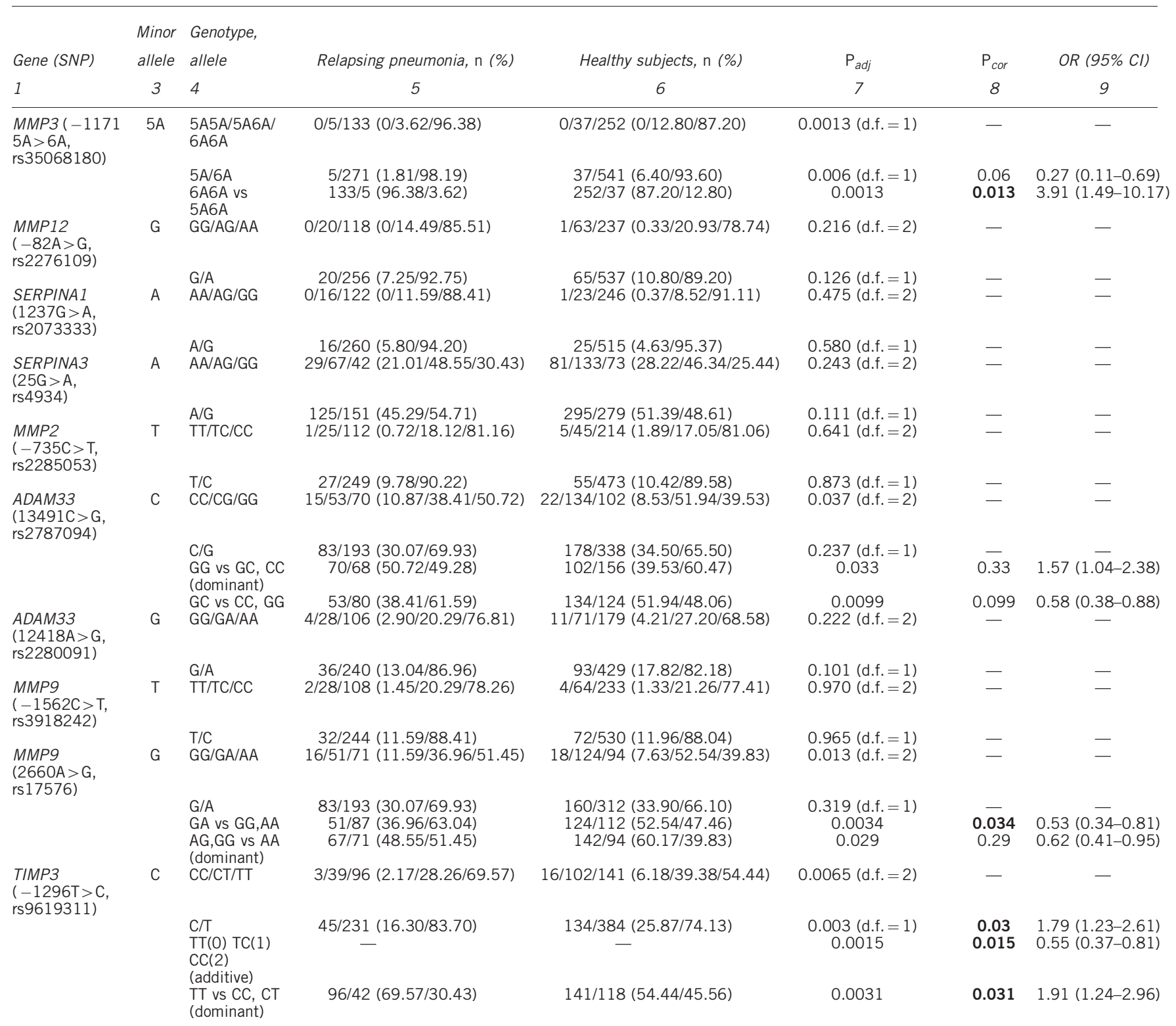

Abbreviations: $\mathrm{Cl}$, confidence interval; d.f., degrees of freedoms; OR, odds ratio.

$P_{\text {adj }}$, significance in the likelihood ratio test for the regression model adjusted for sex and age; $P_{\text {cor }}$, significance after the Bonferroni correction for multiple testing. Bold numerals in the table indicate that the difference was significant after the correction for multiple comparisons.

process is the cause of pathological damage of the lung tissue. ${ }^{4}$ Proteolytic enzymes are considered to be major regulators of inflammatory and immune responses associated not only with the degradation of ECM proteins and the release of ECM-bound interleukins but also with cytokine and chemokine cleavage, and the consequent modulation of the biological activity of inflammation mediators. ${ }^{19,34}$ Increased MMP activity plays an important role in different respiratory diseases damaging the lung tissue and alveolar structure. ${ }^{12,15,35}$ MMP dysregulation can contribute to the pathology of chronic lung disorders, such as asthma, emphysema, COPD, bronchopulmonary dysplasia and cystic fibrosis, acute respiratory distress syndrome and respiratory distress syndrome of the newborn. ${ }^{12-14,16,21}$ Association studies of polymorphic markers in MMPs, ADAM33, TIMPs, SERPINA1 and SERPINA3 genes effecting

Table 4 Linkage disequilibrium between rs3918242 $(-1562 \mathrm{C}>\mathrm{T})$ and rs17576 (2660A $>$ G) MMP9 polymorphisms

\begin{tabular}{|c|c|c|c|c|c|c|c|}
\hline $\begin{array}{l}\text { Locus } 1, \text { rs } 3918242 \\
(-562 C>T)\end{array}$ & $\begin{array}{c}\text { Locus 2, } \\
\text { rs17576 } \\
(2660 A>G)\end{array}$ & $D^{\prime}$ & $\angle O D$ & $r^{2}$ & $\mathrm{Cl}_{\text {low }}$ & $C I_{h i}$ & Dist \\
\hline \multicolumn{8}{|l|}{ Chronic bronchitis } \\
\hline rs3918242 & rs17576 & 0.847 & 17.75 & 0.197 & 0.72 & 0.92 & 4249 \\
\hline \multicolumn{8}{|l|}{ Relapsing pneumonia } \\
\hline rs3918242 & rs17576 & 0.773 & 14.22 & 0.152 & 0.63 & 0.87 & 4249 \\
\hline
\end{tabular}


Table 5 Association of MMP3 ( -1171 5A $>6$ A, rs35068180) and MMP12 ( $-82 \mathrm{~A}>\mathrm{G}$, rs2276109) genes haplotypes with chronic respiratory disease in children

With chronic bronchitis $(\mathrm{N}=420)$

\begin{tabular}{|c|c|c|c|c|c|c|c|c|}
\hline \multirow[b]{2}{*}{$\begin{array}{l}\text { Haplotype } \\
\text { rs35068180-rs2276109 }\end{array}$} & \multirow[b]{2}{*}{$\begin{array}{l}\text { Overall } \\
\text { frequency }\end{array}$} & & \multirow[b]{2}{*}{$\begin{array}{l}\text { Overall } \\
\text { frequency }\end{array}$} & \\
\hline & & $\begin{array}{l}\text { Frequency in } \\
\text { cases/controls }\end{array}$ & OR $(95 \% \mathrm{Cl})$ & $\mathrm{P}_{\text {adj }}$ & & $\begin{array}{l}\text { Frequency in } \\
\text { cases/controls }\end{array}$ & OR $(95 \% \mathrm{Cl})$ & $\mathbf{P}_{\text {adj }}$ \\
\hline $6 \mathrm{~A}-\mathrm{A}$ & 0.8555 & $0.9118 / 0.8326$ & $2.15(1.32-3.52)$ & 0.0012 & 0.8572 & $0.9094 / 0.8326$ & $2.07(1.31-3.27)$ & 0.001 \\
\hline $6 A-G$ & 0.0891 & $0.0546 / 0.1033$ & $0.46(0.24-0.87)$ & 0.017 & 0.0932 & $0.0725 / 0.1033$ & $0.62(0.36-1.07)$ & 0.087 \\
\hline $5 A-A$ & 0.0517 & $0.0336 / 0.0594$ & $0.50(0.22-1.12)$ & 0.093 & 0.046 & $0.0181 / 0.0594$ & $0.27(0.10-0.70)$ & 0.0077 \\
\hline $5 A-G$ & 0.0037 & $0 / 0.0046$ & $0.00(-\operatorname{lnf}-\operatorname{Inf})$ & 1 & 0.0036 & $0 / 0.0046$ & $0.00(-\operatorname{lnf}-\operatorname{Inf})$ & 1 \\
\hline \multicolumn{4}{|c|}{ Haplotype association in general, $P$-value } & 0.011 & & & & 0.0026 \\
\hline
\end{tabular}

Abbreviations: $\mathrm{Cl}$, confidence interval; $N$, is the number of individuals included in the regression analysis; OR, odds ratio.

$P_{\text {adj }}$, significance in the likelihood ratio test for the regression model adjusted for sex and age.

development and progression of COPD, asthma, lung fibrosis and lung cancer were published. ${ }^{12-14,16,21}$ We hypothesized that polymorphic variants of genes functioning in the remodeling of airflow pathways and alveolar destruction may also be associated with severe chronic respiratory diseases in children. We investigated association of MMP1, MMP2, MMP3, MMP9, MMP12, ADAM33, TIMP2, TIMP3, SERPINA1 and SERPINA3 genes polymorphisms with chronic bronchitis and recurrent pneumonia in Tatar children.

In our study, chronic respiratory diseases in children were associated with the MMP9 $(2660 \mathrm{~A}>\mathrm{G})$ polymorphism. The heterozygous genotype at this locus was a factor of resistance to chronic bronchitis and childhood pneumonia. In children with chronic bronchitis and relapsing pneumonia, the frequency of heterozygous genotype was significantly decreased. Strong linkage disequilibrium between the alleles of the $-1562 \mathrm{C}>\mathrm{T}(\mathrm{rs} 3918242)$ and $2660 \mathrm{~A}>\mathrm{G}$ (rs17576) MMP9 polymorphisms was found. Association of MMP9 (2660A > G, rs17576) may be due to the linkage disequilibrium with other SNPs of MMP9 gene. MMP9 hydrolyzes the major components of the lung tissue ECM, denatured collagen and type IV collagen. ${ }^{32,35}$ MMP9 is produced by alveolar macrophages and neutrophils activated by interleukin- 8 and interleukin-1, as well as interleukin-1 inductors, cytokines whose levels are significantly increased in pulmonary or bronchial inflammation. ${ }^{34,35}$ MMP9 levels were increased in bronchoalveolar fluid of patients with COPD and lung emphysema. ${ }^{36}$ MMP9, located on chromosome 20q11.2, contains 13 exons and 12 introns. The $2660 \mathrm{~A}>\mathrm{G}$ polymorphism of $M M P 9$ affects the specific catalytic MMP9 domain responsible for the substrate binding. It results in the amino-acid substitution (Gln279Arg), altering the structure and function of the enzyme. ${ }^{37}$ There have been several studies analyzing the association of MMP9 polymorphisms with respiratory diseases. ${ }^{30,35-38}$ For instance, an analysis of 17 MMP9 polymorphisms in Japanese children with atopic asthma showed that the disease risk was associated with certain MMP9 genotypes. $^{37}$ MMP9 polymorphisms were also associated with allergic rhinitis in children. ${ }^{38}$ The results of our study suggest that MMP9 can be involved in the pathogenesis of not only allergic diseases but also of other inflammatory disorders of the respiratory system in children.

In Tatar children with chronic bronchitis, the portion of homozygous carriers of the frequent A allele of the MMP12 $(-82 \mathrm{~A}>\mathrm{G})$ polymorphism was apparently increased; however, the difference became insignificant after the correction for multiple comparisons $\left(P_{\text {cor }}=0.1\right)$. It was shown that the A allele of MMP12 $(-82 \mathrm{~A}>\mathrm{G})$ had a higher affinity for the AP-1 transcription factor, which results in higher levels of gene expression. ${ }^{19}$ The AA genotype of MMP12 $(-82 \mathrm{~A}>\mathrm{G})$ was associated with decreased respiratory function (forced expiratory volume in $1 \mathrm{~s}$ ) in adult smokers. ${ }^{17}$ Another functional MMP12 polymorphism, 1082A > G (rs652438), has been associated with the severity of asthma and COPD. ${ }^{39}$ MMP12 acts as an important regulator of inflammation and remodeling of respiratory pathways in allergic inflammation, promoting a more severe clinical course of asthma with frequent attacks. ${ }^{39}$ We suppose that treatment including MMP12-inhibiting drugs could be a promising approach in the therapy of asthma and COPD. ${ }^{39,40}$ Our data suggest that MMP12 is more strongly involved in the pathogenesis not only of bronchial asthma but also of childhood chronic bronchitis of non-allergic nature. However, more comprehensive investigations on larger samples are required to confirm these results.

The results of our study demonstrate a significant increase of the frequency of the MMP3 (-1171 5A >6A) 6A6A genotype among children with recurrent pneumonia as compared with healthy children. MMP3, stromelysin-1, is a key enzyme of the MMP family, because it induces and activates the production of other MMPs, such as MMP1 and MMP9, interacts with cytokines and growth factors, and degrades ECM proteoglycans, laminins and type IV collagen in the lung. ${ }^{13,18}$ MMP3 was shown to be involved in lung fibrosis. ${ }^{41}$ The MMP3 (-1171 5A>6A) polymorphism is an insertion-deletion polymorphism altering the binding site for the transcription factor nuclear factor- $\mathrm{\kappa B}$, which affects $M M P 3$ expression. Both in vitro and in vivo experiments showed that the $5 \mathrm{~A}$ allele was associated with two to four times higher levels of $M M P 3$ expression in comparison to 6A. ${ }^{42}$ The $6 \mathrm{~A} 6 \mathrm{~A}$ genotype was associated with rapid decrease in respiratory function characteristics ${ }^{43}$ which agrees with our data. Previously, we detected an association between this genetic variant and COPD. ${ }^{44}$ The association with the frequent genotype may be explained by linkage with another functional polymorphism of MMP3. These results suggest that MMP3 plays an important role in respiratory pathology in adults and in children.

MMP3 is located on chromosome $11 \mathrm{q} 22-\mathrm{q} 23$ in the same cluster as MMP12. Haplotype analysis was performed to investigate the effect of two linked MMP polymorphisms on the risk of chronic bronchitis and recurrent pneumonia in children. We showed that 6A-A haplotype of the MMP3 $(-11715 \mathrm{~A}>6 \mathrm{~A})$ and $M M P 12$ $(-82 \mathrm{~A}>\mathrm{G})$ genes was associated with increased risk of chronic bronchitis $(\mathrm{OR}=2.15)$ and recurrent pneumonia $(\mathrm{OR}=2.07)$ in children. These results confirm the association revealed by the analysis of single loci of MMP3 $(-11715 \mathrm{~A}>6 \mathrm{~A})$ and $M M P 12(-82 \mathrm{~A}>\mathrm{G})$ and indicate the significance of MMP12 and MMP3 in chronic bronchitis and recurrent pneumonia pathogenesis.

We also found that the presence of the TT genotype of TIMP3 $(-1296 \mathrm{~T}>\mathrm{C})$ polymorphism is associated with increased risk of recurrent pneumonia. Probably, TIMP3 has a substantial part in 
predisposition to lung parenchymal injury resulting from long-term pulmonary infections in children. TIMP3 is different from the other TIMP proteins as it inhibits a wide range of proteolytic enzymes, including not only MMPs but also ADAMs, in particular ADAM33. ${ }^{25}$ TIMP3 regulates the release of tumor growth factor $\beta 1$ and tumor necrosis factor- $\alpha$ in response to tissue damage or inflammation. ${ }^{45}$ TIMP3 is located on chromosome 22 (22q12.1-q13.2) within the long intron 5 of SYN3. ${ }^{46}$ The $-1296 \mathrm{~T}>\mathrm{C}$ polymorphism of the TIMP3 promoter region probably affects its transcriptional activity, but its functional significance has not yet been studied. ${ }^{14,46}$ Some evidence implicates TIMP3 in the regulation of inflammation following acute lung tissue damage. ${ }^{14}$ Recently, we identified an association of TIMP3 $(-1296 \mathrm{~T}>\mathrm{C})$ with the risk of development of COPD in non-smokers. ${ }^{44}$

Our findings indicate that polymorphisms of the ADAM33 gene may play a role in the susceptibility to severe lung injury in cases of children with recurrent pneumonia. ADAM33 is located on chromosome 20p13, comprises 22 exons and is expressed mainly in lung fibroblasts and in bronchial smooth muscle cells. ${ }^{47}$ ADAM33 is involved in the enhancement of the immune response and lung tissue proteolysis, as well as in angiogenesis. ${ }^{47}$ Proteolysis is mediated by the ADAM33driven release of membrane-bound cytokines, growth factors and their receptors, and $\alpha 2$-macroglobulin degradation. ${ }^{21,22}$ ADAM33 contains a number of polymorphic loci, many of which are functional. ${ }^{47}$ The polymorphisms $12418 \mathrm{~A}>\mathrm{G}$ and $13491 \mathrm{C}>\mathrm{G}$ are located in exons 20 and 22 , which encode the cytoplasmic domain, respectively. Changes in the structure of these regions can result in alternative splicing of the ADAM33 transcript and affect intracellular signaling. ${ }^{22,47}$ Different ADAM33 polymorphisms are associated with protein overexpression, or produce enzyme isoforms that cause pathological remodeling of lung tissue and smooth muscles, and also induce the release of large quantities of cytokines, aggravating inflammation. ${ }^{24}$ The association of ADAM33 polymorphisms with COPD and bronchial asthma was reported previously. ${ }^{22,23,47,48}$ Therefore, changes in ADAM33 activity may influence the inflammatory process in bronchial and lung systems at various stages of its development.

The hyperproduction of MMPs, either as a result of acute inflammation or due to polymorphism of the genes responsible for enzyme production, causes pathological ECM destruction and induces intensive lung tissue remodeling, affects physiological lung growth and leads to structural reorganization of the bronchial tree and pathological lung tissue damage in children with chronic respiratory diseases.

In summary, we found that the MMP9, MMP3 and TIMP3 polymorphisms and MMP3 and MMP12 haplotypes were associated with chronic bronchitis and recurrent pneumonia in Tatar children. Previously, we showed that chronic bronchitis and recurrent pneumonia in children were associated with polymorphisms of the biotransformation enzyme genes (CYP1A1, CYP2E1 and GSTT1). ${ }^{49}$ Further replication study in independent samples of cases and controls and in other ethnical cohorts is needed for confirmation of our results.

\section{ACKNOWLEDGEMENTS}

This work was supported by the Russian Foundation for Basic Research and the Russian Scientific Foundation for Humanities.

1 Silverman, E. K., Vestbo, J., Agusti, A., Anderson, W., Bakke, P. S., Barnes, K. C. et al Opportunities and challenges in the genetics of COPD 2010: an International COPD Genetics Conference report. COPD 8, 121-135 (2011).

2 Cookson, W. O. \& Moffatt, M. F. Genetics of complex airway disease. Proc. Am. Thorac. Soc. 8, 149-153 (2011)
3 Cho, M. H., Castaldi, P. J., Wan, E. S., Siedlinski, M., Hersh, C. P., Demeo, D. L. et al. A genome-wide association study of COPD identifies a susceptibility locus on chromosome 19q13. Hum. Mol. Genet. 21, 947-957 (2012).

4 Wan, Y. I., Shrine, N. R., Soler Artigas, M., Wain, L. V., Blakey, J. D., Moffatt, M. F. et al. Genome-wide association study to identify genetic determinants of severe asthma. Thorax. 67, 762-768 (2012).

5 Thébaud, B. Update in pediatric lung disease 2010. Am. J. Respir. Crit. Care Med. 183, 1477-1481 (2011).

6 Sandford, A. J., Weir, T. D., Spinelli, J. J. \& Paré, P. D. Z and S mutations of the alphal-antitrypsin gene and the risk of chronic obstructive pulmonary disease. Am. J. Respir. Cell. Mol. Biol. 20, 287-291 (1999).

7 DeMeo, D. L., Hersh, C. P., Hoffman, E. A., Litonjua, A. A., Lazarus, R., Sparrow, D. et al. Genetic determinants of emphysema distribution in the national emphysema treatment trial. Am. J. Respir. Crit. Care Med. 176, 42-48 (2007).

8 Preston, J. A., Beagley, K. W., Gibson, P. G. \& Hansbro, P. M. Genetic background affects susceptibility in nonfatal pneumococcal bronchopneumonia. Eur. Respir. J. 23, 224-231 (2004)

9 Lands, L. C., Allen, J., Cloutier, M., Leigh, M., McColley, S. \& Murphy, T. ATS Consensus Statement: research opportunities and challenges in pediatric pulmonology. Am. J. Respir. Crit. Care Med. 172, 776-780 (2005).

10 Payne, D. N., Saglani, S. \& Bush, A. in Respiratory Diseases in Infants and Children (eds Frey, U. \& Gerritsen, J.) Vol. 37 ch. 4, 41-59 (European Respiratory Society Monograph, 2006).

11 Lodha, R., Puranik, M., Natchu, U. C. \& Kabra, S. K. Recurrent pneumonia in children: clinical profile and underlying causes. Acta Paediatr. 91, 1170-1173 (2002).

12 Kong, M. Y., Gaggar, A., Li, Y., Winkler, M., Blalock, J. E. \& Clancy, J. P. Matrix metalloproteinase activity in pediatric acute lung injury. Int. J. Med. Sci. 6, 9-17 (2009).

13 Fang, S., Jin, X., Wang, R., Li, Y., Guo, W., Wang, N. et al. Polymorphisms in the MMP1 and MMP3 promoter and non-small cell lung carcinoma in North China. Carcinogenesis 26, 481-486 (2005).

14 Gill, S. E., Huizar, I., Bench, E. M., Sussman, S. W., Wang, Y., Khokha, R. et al. Tissue inhibitor of metalloproteinases 3 regulates resolution of inflammation following acute lung injury. Am. J. Pathol. 176, 64-67 (2010).

15 Greenlee, K. J., Werb, Z. \& Kheradmand, F. Matrix metalloproteinases in lung: multiple, multifarious, and multifaceted. Physiol. Rev. 87, 69-98 (2007).

16 Hirano, K., Sakamoto, T., Uchida, Y., Morishima, Y., Masuyama, K., Ishii, Y. et al. Tissue inhibitor of metalloproteinases-2 gene polymorphisms in chronic obstructive pulmonary disease. Eur. Respir. J. 18, 748-752 (2001).

17 Hunninghake, G. M., Cho, M. H., Tesfaigzi, Y., Soto-Quiros, M. E., Avila, L., Lasky-Su, J. et al. MMP12, lung function, and COPD in high-risk populations. N. Engl. J. Med. 361, 2599-2608 (2009).

18 González-Arriaga, P., Pascual, T., García-Alvarez, A., Fernández-Somoano, A., López-Cima, M. F. \& Tardón, A. Genetic polymorphisms in MMP 2, 9 and 3 genes modify lung cancer risk and survival. BMC Cancer 12, 121 (2012).

19 Lagente, V. \& Boichot, E. Role of matrix metalloproteinases in the inflammatory process of respiratory diseases. J. Mol. Cell. Cardiol. 48, 440-444 (2010).

20 Affara, M., Dunmore, B. J., Sanders, D. A., Johnson, N., Print, C. G. \& Charnock-Jones, D. S. MMP1 bimodal expression and differential response to inflammatory mediators is linked to promoter polymorphisms. BMC Genom. 12, 43 (2011).

21 Holgate, S. T. ADAM metallopeptidase domain 33 (ADAM33): identification and role in airways disease. Drug News Perspect. 23, 381-387 (2010).

22 Wang, X., Li, L., Xiao, J., Jin, C., Huang, K., Kang, X. et al. Association of ADAM33 gene polymorphisms with COPD in a northeastern Chinese population. BMC Med. Genet. 10, 132-139 (2009).

23 Awasthi, S., Tripathi, P., Ganesh, S. \& Husain, N. Association of ADAM33 gene polymorphisms with asthma in Indian children. J. Hum. Genet. 56, 188-195 (2011).

24 Paulissen, G., Rocks, N., Gueders, M. M., Crahay, C., Quesada-Calvo, F., Bekaert, S. et al. Role of ADAM and ADAMTS metalloproteinases in airway diseases. Respir. Res. 10, 127-135 (2009)

25 Brew, K. \& Nagase, H. The tissue inhibitors of metalloproteinases (TIMPs): an ancient family with structural and functional diversity. Biochim. Biophys. Acta 1803, 55-71 (2010).

26 International Statistical Classification of Diseases and Related Health Problems, Tenth Revision (ICD-10 http://www.who.int/classifications/icd/en/)

27 Mathew, C. G. P. in The Isolation of High Molecular Weight Eukaryotic DNA in Methods in Molecular Biology (ed Wolker, J. M.) Vol. 2 ch. 5 31-34 (Springer: Berlin, 1985).

28 Noll, W., Belloni, D., Rutter, J., Storm, C., Schned, A., Titus-Ernstoff, L. et al. Loss of heterozygosity on chromosome $11 \mathrm{q} 22-23$ in melanoma is associated with retention of the insertion polymorphism in the matrix metalloproteinase-1 promoter. Am. J. Pathol 158, 691-677 (2001)

29 Armstrong, C., Abilleira, S., Sitzer, M., Markus, H. S. \& Bevan, S. Polymorphisms in MMP family and TIMP genes and carotid artery intima-media thickness. Stroke 38, 2895-2899 (2007).

30 Joos, L., He, J. Q., Shepherdson, M. B., Connett, J. E., Anthonisen, N. R., Pare, P. D. et al. The role of matrix metalloproteinase polymorphisms in the rate of decline in lung function. Hum. Mol. Genet. 11, 569-576 (2002).

31 Gnasso, A., Motti, C., Irace, C., Carallo, C., Liberatoscioli, L., Bernardini, S. et al. Genetic variation in human stromelysin gene promoter and common carotid geometry in healthy male subjects. Arterioscler. Thromb. Vasc. Biol. 20, 1600-1605 (2000).

32 Ganter, K. Deichmann, K. A \& Heinzmann, A. Association study of polymorphisms within matrix metalloproteinase 9 with bronchial asthma. Int. J. Immunogenet. 32 233-236 (2005). 
33 Zhou, M., Huang, Sh., Wan, H.-Y., LI, B., Drng, W. \& Li, M. Genetic polymorphism in matrix metalloproteinase- 9 and the susceptibility to chronic obstructive pulmonary disease in Han population of south China. Chin. Med. J. 117, 1481-1484 (2004).

34 Van Lint, P. \& Libert, C. Chemokine and cytokine processing by matrix metalloproteinases and its effect on leukocyte migration and inflammation. J. Leukocyte Biol. 82 1375-1381 (2007).

35 Yoon, H. K., Cho, H. Y. \& Kleeberger, S. R. Protective role of matrix metalloproteinase-9 in ozone-induced airway inflammation. Environ. Health Perspect. 115, 1557-1563 (2007).

36 Zhou, M., Huang, Sh., Wan, H.-Y., LI, B., Drng, W. \& Li, M. Genetic polymorphism in matrix metalloproteinase-9 and the susceptibility to chronic obstructive pulmonary disease in Han population of south China. Chin. Med. J. 117, 1481-1484 (2004)

37 Nakashima, K., Hirota, T., Obara, K., Shimizu, M., Doi, S., Fujita, K. et al. A functional polymorphism in MMP-9 is associated with childhood atopic asthma. Biochem. Biophys. Res. Commun. 344, 300-307 (2006).

38 Inoue, H., Mashimo, Y., Funamizu, M., Yonekura, S., Horiguchi, S., Shimojo, N. et al. Association of the MMP9 gene with childhood cedar pollen sensitization and pollinosis. J. Hum. Genet. 57, 176-183 (2012).

39 Mukhopadhyay, S., Sypek, J., Tavendale, R., Gartner, U., Winter, J., Li, W. et al. Matrix metalloproteinase-12 is a therapeutic target for asthma in children and young adults. J. Allergy Clin. Immunol. 126, 70-76 (2010).

40 Mocchegiani, E., Giacconi, R. \& Costarelli, L. Mettalloproteases/anti-metalloproteses imbalance in chronic obstructive pulmonary disease: genetic factors and treatment implications. Curr. Opin. Pulm. Med. 17, S11-S19 (2011).

41 Yamashita, C. M., Dolgonos, L., Zemans, R. L., Young, S. K., Robertson, J., Briones, N. et al. Matrix metalloproteinase 3 is a mediator of pulmonary fibrosis. Am. J. Pathol. 179, 1733-1745 (2011)
42 Souslova, V., Townsend, P. A., Mann, J., van der Loos, C. M., Motterle, A., D’Acquisto F. et al. Allele-specific regulation of matrix metalloproteinase-3 gene by transcription factor NFkappaB. PLoS One. 5, e9902 (2010)

43 Santus, P., Casanova, F., Biondi, M. L., Blasi, F., Di Marco, F. \& Centanni, S Stromelysin-1 polymorphism as a new potential risk factor in progression of chronic obstructive pulmonary disease. Monaldi. Arch. Chest Dis. 71, 15-20 (2009).

44 Korytina, G. F., Tselousova, O. S., Akhmadishina, L. Z., Viktorova, E. V., Zagidullin, Z. \& Viktorova, T. V. Association of MMP3, MMP9, ADAM33, and TIMP3 polymorphisms with chronic obstructive pulmonary disease and its progression. Mol. Biol. 46, 438-449 (2012).

45 Kassiri, Z., Defamie, V., Hariri, M., Oudit, G. Y., Anthwal, S., Dawood, F. et al Simultaneous transforming growth factor beta-tumor necrosis factor activation and cross-talk cause aberrant remodeling response and myocardial fibrosis in Timp3deficient heart. J. Biol. Chem. 284, 29893-29904 (2009).

46 Hammani, K., Henriet, P., Silbiger, S. M. \& DeClerck, Y. A. Cloning and partia structure of the gene encoding human tissue inhibitor of metalloproteinases-3. Gene 170, 287-288 (1996).

47 Van Eerdewegh, P., Little, R. D., Dupuis, J., Del Mastro, R. G., Falls, K., Simon, J. et al. Association of the ADAM33 gene with asthma and bronchial hyperresponsiveness. Nature 418, 426-430 (2002)

48 Pabst, S., Pizarro Touron, C., Gillissen, A., Lennarz, M., Tuleta, I., Nickenig, G. et al. ADAM33 gene polymorphisms in chronic obstructive pulmonary disease. Eur. J. Med. Res. 14, 182-186 (2009).

49 Korytina, G. F., Yanbaeva, D. G., Babenkova, L. I. Etkina, E I. \& Victorova, T. V. Genetic polymorphisms in the cytochromes $P-450$ (1A1, 2E1), microsomal epoxide hydrolase and glutathione $S$-transferase $M 1, T 1$, and $P 1$ genes, and their relationship with chronic bronchitis and relapsing pneumonia in children. J. Mol. Med. 83, 700-710 (2005). 